\title{
Fibroblast Growth on Nanofiber Material Matrices and Changes to Their Mechanical Properties
}

\author{
Peteris Stradins, Martins Kalejs, Viktorija Priedite, Romans Lacis, Iveta Ozolanta, Modra Murovska, \\ and Vladimir Kasyanov
}

\begin{abstract}
Polycaprolactone (PCL) and gelatin electrospun nanofiber matrices are very promising for heart valve tissue engineering. The main aim of this study was to test the growth capability of fibroblasts on these materials and to determine their effect on the mechanical properties of the tested materials.

Matrices from PCL and gelatin were placed in standard 8-well culture plates and cultured for six weeks with COS-7 cells. Viability of cells was assessed by acridine orange and ethidium bromide staining. Mechanical properties were compared before and after culture with COS-7 using uniaxile tensile tests.

In tested conditions proportion of viable cells after 6 weeks of culture constituted $\mathbf{2 0 0 \%}$, with no significant differences between materials and samples. Significant reduction in maximum stress was seen for $P C L$, from $0.49 \pm 0.01 \mathrm{MPa}$ to $0.37 \pm 0.03 \mathrm{MPa}(p<0.05)$. Deformability of gelatin increased from $87.2 \pm 13.8 \%$ to $157.1 \pm 15.2 \%(p<0.05)$ after 6 weeks in culture. Modulus of elasticity did not change significantly for both tested materials.

We conclude that both materials are suitable for tissue engineering purposes due to their biocompatibility, but the rather prominent changes in mechanical features of gelatin raise some doubts about its use as stand-alone scaffold material.
\end{abstract}

Index Terms-Fibroblasts, heart valve, nanofibers, tissue engineering

\section{INTRODUCTION}

Heart valve tissue engineering is a rapidly evolving field with promises to offer a solution for heart valve replacement procedures, a solution which would be better than currently applied biological or mechanical heart valve prostheses. It gives us hope of creating heart valve prostheses - substitutes from living tissue capable of repair and possibly growth, which would eliminate the pitfalls of the current surgical prostheses.

Currently the treatment for end-stage valvular disease is surgical replacement with either a mechanical or bioprosthetic prosthesis. Mechanical prostheses offer

Manuscript received February 27, 2013; revised March 29, 2013.This work was in part supported by Latvian National Research Program in Medicine 2010.-2013., project "Research of Biomaterials for Treatment of Cardiovascular diseases" and European Social Found [Agreement Nr. 2009/0221/1DP/1.1.1.2.0/09/APIA/VIAA/074].

P. Stradins and M. Kalejs were with Augusts Kirhensteins Institute of Microbiology and Virology, Ratsupites str. 5, Riga, Latvia and still are with Department of Cardiac Surgery, Pauls Stradins Clinical University Hospital, Pilsonu str. 13, Riga, Latvia (e-mail: peteris.stradins@stradini.lv, martins.kalejs@stradini.lv).

V. Priedite, R. Lacis, I. Ozolanta, M. Murovska, and V. Kasyanov are with Augusts Kirhensteins Institute of Microbiology and Virology, Ratsupites str. 5, Riga, Latvia (e-mail: teirpriedite@gmail.com, modra.murovska@rsu.lv, valentina@stradini.lv, Kasyanov@latnet.lv). excellent durability, but being a foreign non-physiological material in the bloodstream they cause increased risk of endocarditis as well as even more importantly risk of thrombosis, which calls for life-long anticoagulation with all the possible side-effects associated with it [1].

Biological prostheses are most often of xenogenic origin porcine aortic valves or bioprostheses made from bovine pericardium [2]. Although bioprostheses are significantly less thrombogenic their durability is limited and the rate of their degradation is recipient age-dependant, making them more suitable for the patient older than 65 years and much less recommendable in younger patients due to a potential need for a repeat procedure in future [3], [4]

There have been many attempts to create a heart valve replacement with capabilities to grow and repair itself using tissue engineering techniques. With this approach patients own cells, isolated from blood, fatty tissue, bone marrow or other sources, are seeded on a premade - valve leaflet-shaped starter matrix, which must be able to support cell growth and cell-to-cell interactions required to form the structures typical to a heart valve leaflet. The two principal types of starter-matrices used are either of biological or synthetic origin, respectively; they can be either decellularized xenogenic or allogenic fixed valve leaflets or they can be made from biocompatible and biodegradable polymers. Decellularization has been applied with varying success in many studies [5], but in general it is a very tedious method with a very fragile balance between the requirement to remove all the cellular material, to prevent immunogenic reactions, and to maintain the extracellular matrix (ECM) structures relatively undamaged, for better and faster reseeding with patients cells and to provide a mechanically sufficient scaffold. An ideal synthetic matrix should be biocompatible, biodegradable and of course technically reproducible. Besides that the scaffold should also have a cell-friendly surface and similar mechanical properties to the native heart valves. To guarantee stability after implantation the rate of scaffold degradation shouldn't exceed that of new ECM fiber production. Keeping this in mind it is of special interest to stress that the ideal matrix must be not only mechanically strong enough to withstand the pressures after implantation but also deformable enough, because it has been demonstrated that ECM formation by valve interstitial cells is strongly dependant on the stiffness/deformability of the scaffold [6], [7]. Minimum time required for de-novo ECM formation is $6-8$ up to 20 weeks which also would be the time a scaffold has to maintain its mechanical properties, before it can be replaced by the newly formed tissue [8]. 


\section{THE AIM}

Objective of our study was to evaluate two polymer nanofiber materials for use as a matrix for heart valve tissue engineering purposes by testing their biocompatibility for COS-7 cells in vitro and by evaluating their mechanical stability and rate of degradation by assessing their mechanical properties after a prolonged culture with these fibroblast-like cells.

\section{MATERIALS AND METHODS}

Electrospun nanofiber materials were ordered custom-made by Elmarco s.r.o., (Liberec, Czech Republic) from gelatin type A with density of $5.7 \mathrm{~g} / \mathrm{m}^{2}$ and $0.1 \mathrm{~mm}$ thickness and polycaprolactone (PCL) with a density of 15.7 $\mathrm{g} / \mathrm{m}^{2}$, thickness $-0.29 \mathrm{~mm}$.

Tested material samples were placed in standard 8-well culture plates and cultured for six weeks with COS-7 cells, originally derived from an African Green Monkey kidney fibroblast cell line (ATCC 1651 CRL). Cells were maintained in Dulbecco's Modified Eagle Medium (DMEM) with 5\% fetal calf serum at $37^{\circ} \mathrm{C}$ in humidified $5 \% \mathrm{CO} 2$ atmosphere. Culture media were changed twice a week. After six weeks of culture viability of the cells was assessed microscopically by acridine orange and ethidium bromide staining.

Mechanical properties were analyzed using an uni-axial universal testing machine Zwick/Roell BDO-FB0.5TS (Zwick GmbH \& Co, Ulm, Germany) equipped with test Xpert software (see Fig.1). The tested nanofiber scaffolds were cut into $3.5 \mathrm{~mm}$ wide and $15-20 \mathrm{~mm}$ long specimens. The thickness of all specimens was measured using a cathetometer MK-6 (LOMO, Saint Petersburg, Russia) with a precision of $\pm 0.01 \mathrm{~mm}$. Data are presented as means \pm standard deviation. Paired Student's t-test was used for statistical comparisons.

\section{RESULtS}

In tested conditions COS-7 cells were growing well on both nanofiber materials forming an uniform monolayer, see Fig. 2. Proportion of viable cells after 6 weeks of culture constituted $92.6 \pm 7.4 \%$ on PCL material and $88.1 \pm 5.7 \%$ on gelatin samples, with no significant differences between materials and samples.

TABLE I: SUMMARY OF MECHANICAL PROPERTIES OF PCL AND GELATIN SAMPLES BEFORE AND AFTER CULTURE WITH GREEN MONKEY FiBROBLASTS FOR 6 WeEkS. MOdUlus of Elasticity (E), Ultimate STRESS ( $\Sigma$ M) AND Ultimate Strain $(\Sigma X)$ ARE SHOWn

\begin{tabular}{|l|c|c|c|}
\hline & $\begin{array}{c}\text { Max stress } \\
(\mathrm{Mpa})\end{array}$ & Max strain (\%) & $\begin{array}{c}\text { Modulus of } \\
\text { elasticity (Mpa) }\end{array}$ \\
\hline PCL & $0.49 \pm 0.01$ & $34.7 \pm 4.0$ & $2.1 \pm 0.1$ \\
\hline PCL (6 w. COS-7) & $0.37 \pm 0.03$ & $28.5 \pm 1.0$ & $2.2 \pm 0.1$ \\
\hline Gelatin & $0.43 \pm 0.09$ & $87.2 \pm 13.8$ & $0.73 \pm 0.17$ \\
\hline Gelatin (6 w. COS-7) & $0.45 \pm 0.08$ & $157.1 \pm 15.2$ & $0.62 \pm 0.16$ \\
\hline
\end{tabular}

Results of the mechanical properties testing of the two nanofiber materials before and after culture with COS-7 cells are summarized in Table I. Significant reduction in maximum stress was seen for PCL, from $0.49 \pm 0.01 \mathrm{MPa}$ to $0.37 \pm 0.03 \mathrm{MPa}(p<0.05)$, see Fig. 3a. On the other hand deformability of gelatin after 6 weeks cultivation with COS-7 increased from $87.2 \pm 13.8 \%$ to $157.1 \pm 15.2 \%$ ( $p<0.05)$, see Fig. 3b. Modulus of elasticity did not change significantly for both tested materials $-2.1 \pm 0.1 \mathrm{MPa}$ before and $2.2 \pm 0.1 \mathrm{MPa}$ after cultivation with the fibroblast cell line for PCL and $0.73 \pm 0.17 \mathrm{MPa}$ and $0.62 \pm 0.16 \mathrm{MPa}$ for gelatin respectively.

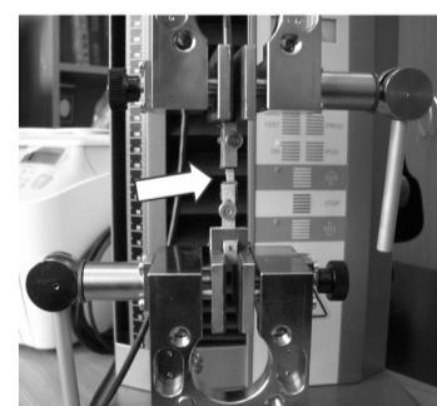

Fig. 1. The setup for uni-axial tensile tests with a universal testing machine Zwick/Roell BDO-FB0.5TS (Zwick GmbH \& Co, Ulm, Germany) equipped with test Xpert software. Analyzed material sample marked with an arrow.

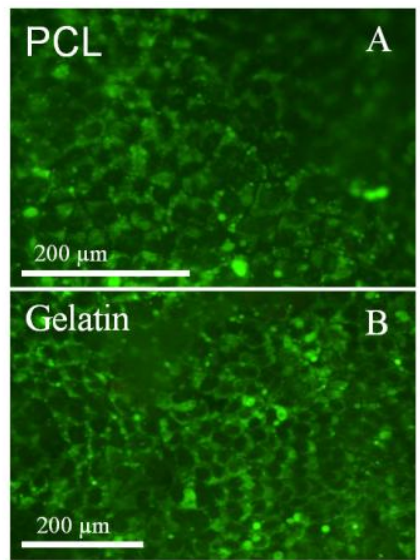

Fig. 2. Fluorescence microscopy images of COS-7 culture grown on PCL (A) and gelatin (B) samples for 6 weeks, acridine orange and ethidium bromide staining.

\section{DisCUSSION AND CONCLUSIONS}

Polymer scaffolds have been used for tissue engineering purposes with varying success for many years already [8]. Various polymers - natural and synthetic, their combinations and modified molecules have been tested for different tissue engineering tasks [9]-[11]. Many polymer scaffold types have been used previously for cardiac and cardiac valve tissue engineering [7], [8], [12]. Most interestingly there is recent data that one of our studied polymers - PCL containing several modifications and used in combination with polyethylene glycol can promote cardiomyogenic embryonic stem cell differentiation [13].

Both of the tested materials are widely studied and well known: one of them - polycaprolactone has been used as a material in surgery for decades with mechanical and biological properties, including biodegradation well described [14], [15]. Still to our best knowledge there are no published studies comparing mechanical properties of these two polymer nanofiber materials before and after prolonged cell culture. 
PCL is an ideal candidate of tissue engineering scaffold for load bearing components, like cartilage and bone as well as heart valve tissue due to its slow degradation rate in vivo [14]. It has been shown that phagocytosis of PCL occurs after molecular weight of the polymer is reduced to 3000 or less by nonenzymatic hydrolysis of the ester linkages, which occurs after $\sim 6$ months in vivo [15]. Although our results show significant reduction of maximum stress of PCL matrices after 6 weeks of culture, this reduction of $25 \%$ is rather technically non-significant, because in the physiological conditions loading of the valve would never reach those tested and, as can be seen both in Table I and Fig. 3, modulus of elasticity (the slope of the graph) remains unchanged for the samples before and after culture.
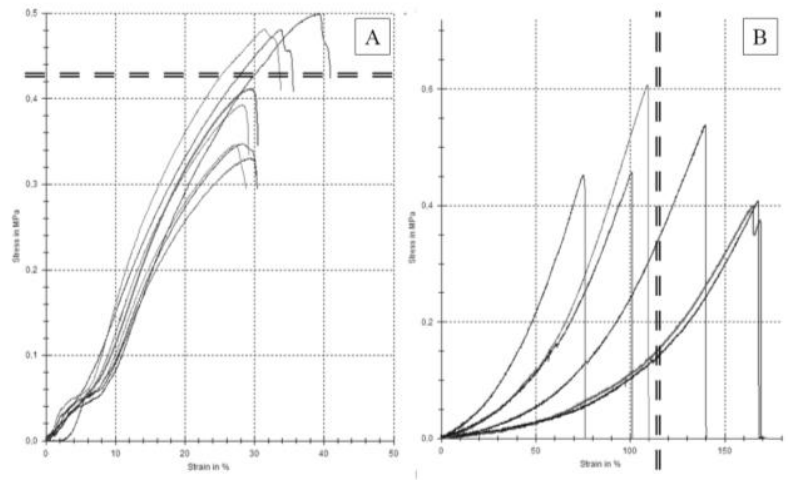

Fig. 3. Stress - strain curves of PCL and Gelatin from one of the experiments showing in a single graph both samples before and after culture with COS-7 cells. A: PCL samples - curves exceeding the double-dashed line correspond to those before culture, B: gelatin samples - curves to the left of the double-dashed line correspond to those before culture.

Gelatin although commercially widely used still remains a rather poorly understood substance manufactured from native collagen. Still it is rather very popular on the modern biomedical scene, being exploited as a drug and cell carrier/scaffold [10], [16]. It's mechanical properties and biodegradation both in vivo and in vitro has been extensively studied [10], [17]. In our study gelatin after 6 weeks in culture didn't lose its mechanical strength, but gained more deformability, which cannot be explained without ultrastructural studies. This in praxis could lead to problems in practical application of heart valve tissue engineered constructs with a scaffold made only from gelatin, because it could result in excess bulging and even prolapse of valve leaflets.

The main limitation of our study is that it has been carried out in an in vitro setting - namely data from a cell culture cannot be extrapolated to an in vivo situation with its highly dynamic environment in the circulatory system and exposure to high dynamic pressures. General conclusions about biocompatibility cannot be drawn from a study with COS-7 cells.

Our study has shown that both of the tested materials are suitable candidates for tissue engineering of heart valve substitutes. Both of them demonstrate good biocompatibility for COS-7 cells with $~ 90 \%$ of viable cells in the culture after 6 weeks, forming a monolayer which covers the entire sample.

The rather prominent changes in mechanical features of gelatin raise some doubts about its use as stand-alone scaffold material, judged by our findings it should be used together with other polymers, i.e. with PCL.

\section{REFERENCES}

[1] S. H. Rahimtoola, "Choice of prosthetic heart valve in adults," J Am Coll Cardiol, vol. 55, pp. 2413-2426, Jun. 2010.

[2] F. J. Schoen and R. J. Levy, "Founder's Award, 25th Annual Meeting of the Society for Biomaterials Perspectives," Providence, RI, April 28-May 2, 1999. Tissue heart valves: current challenges and future research perspectives," J. Biomed. Mater. Res, vol. 47, pp. 439-465, Dec. 1999

[3] I. Vesely, "The evolution of bioprosthetic heart valve design and its impact on durability," Cardiovascular Pathology, vol. 12, pp. 277-286, Sep.- Oct. 2003.

[4] F. J. Schoen, "Cardiac valves and valvular pathology: update on function, disease, repair, and replacement," Cardiovasc Pathol, vol. 14, pp. 189-194, Jul. - Aug. 2005.

[5] K. Mendelson and F. J. Schoen, "Heart valve tissue engineering: concepts, approaches, progress, and challenges," Ann Biomed Eng, vol. 34, pp. 1799-1819, Oct. 2006.

[6] A. M. Quinlan and K. L. Billiar, "Investigating the role of substrate stiffness in the persistence of valvular interstitial cell activation," $J$ Biomed Mater Res A, vol. 100, no. 9, pp. 2474-2482, Sep. 2012.

[7] A. Mol, A. I. Smits, C. V. Bouten, and F. P. Baaijens, "Tissue engineering of heart valves: advances and current challenges," Expert Rev Med Devices, vol. 6, no. 3, pp. 259-275, May 2009.

[8] D. Schmidt, U. A. Stock, and S. P. Hoerstrup, "Tissue engineering of heart valves using decellularized xenogeneic or polymeric starter matrices," Philos Trans $R$ Soc Lond B Biol Sci, vol. 362, pp. 1505-1512, Aug. 2007.

[9] S. Chung and M. W. King, "Design concepts and strategies for tissue engineering scaffolds," Biotechnol Appl Biochem, vol. 58, no. 6, pp. 423-438, Nov. - Dec. 2011.

[10] M. Li, M. J. Mondrinos, M. R. Gandhi, F. K. Ko, A. S. Weiss, and P. I. Lelkes, "Electrospun protein fibers as matrices for tissue engineering," Biomaterials, vol. 26, no. 30, pp. 5999-6008, Oct. 2005

[11] I. O. Smith, X. H. Liu, L. A. Smith, and P. X. Ma, "Nanostructured polymer scaffolds for tissue engineering and regenerative medicine," Wiley Interdiscip Rev Nanomed Nanobiotechnol, vol. 1, no. 2, pp 226-236, Mar. - Apr. 2009.

[12] R. A. Rippel, H. Ghanbari, and A. M. Seifalian, "Tissue-engineered heart valve: future of cardiac surgery," World J Surg, vol. 36, no. 7, pp. 1581-1591, Jul. 2012.

[13] M. K. Gupta, J. M. Walthall, R. Venkataraman, S. W. Crowder, D. K. Jung, and S. S. Yu et al., "Combinatorial polymer electrospun matrices promote physiologically-relevant cardiomyogenic stem cell differentiation," PLoS One, vol. 6, no. 12, pp. 28935, Dec. 2011.

[14] S. C. Woodward, P. S. Brewer, and F. Moatamed, "The intracellular degradation of poly(e-caprolactone)," Journal of Biomedical Materials Research, vol. 19, no. 4, pp. 437-444, Apr. 1985.

[15] C. G. Pitt, F. I. Chasalow, Y. M. Hibionada, D. M. Klimas, and A Schindler, "Aliphatic polyesters. I. The degradation of poly (e-caprolactone) in vivo," Journal of Applied Polymer Science, vol. 26 , no. 11, pp. 3779-3787, Nov. 1981.

[16] A. Kumari, S. K. Yadav, and S. C. Yadav, "Biodegradable polymeric nanoparticles based drug delivery systems," Colloids Surf B Biointerfaces, vol. 75, no. 1, pp. 1-18, Jan. 2010.

[17] E. van den Bosch and C. Gielens, "Gelatin degradation at elevated temperature," Int J Biol Macromol, vol. 32, no. 3-5, pp. 129-138, Sep. 2003.

Peteris Stradins was born in Riga, Latvia, 1971. He received MD at Medical Academy Of Latvia, Riga, Latvia in 1995. PhD in Medicine in the field of biomechanics of the human cardiovascular system from Riga Stradins University, Riga, Latvia in 2004. His main research interests are biomechanics of the cardiovascular system, mainly heart valves and their components as well as clinical investigation.

He currently holds a position of an associate professor of Cardiac Surgery at Riga Stradins University, Riga, Latvia as well as he is Chief of the Department of Cardiac Surgery at Pauls Stradins Clinical University Jospital, Riga, Latvia.

Prof. Stradins is a member of many local and international professional societies including but not limited to: European Society of Cardiology, European Association for Cardio-Thoracic Surgery, Society of Thoracic Surgeons, European Society For Clinical Investigation and many others. 
Martins Kalejs was born in Talsi, Latvia, 1981, who received MD at Riga Stradins University, RigaLatvia in 2006. Currently has finished his formal $\mathrm{PhD}$ studies and is a PhD candidate at Riga Stradins University. His main research interests are biomechanics of the cardiovascular system, mainly heart valves as well as modeling of the cardiovascular system.

$\mathrm{He}$ currently is a staff surgeon at the Department of Cardiac Surgery at Pauls Stradins Clinical University Hospital,Riga, Latvia and a researcher at Riga Stradins University, Riga, Latvia.

Dr. Kalejs is a member of several local and international professional societies including but not limited to: European Society of Cardiology, European Association for Cardio-Thoracic Surgery, Scandinavian Association for Thoracic Surgery and others.

Viktorija Priedite was born in Riga, Latvia, 1961, who received MSc in Biology at the University of Latvia in 1995. Currently is a PhD student at Riga Stradins University - Doctoral program in Medicine an Pharmacy. Authors main research interests are clinical immunology and cellular immunology.

She currently works in a privately held laboratory Biocon in Riga, Latvia. Previously has been a researcher at August Kirchenstein Institute of Microbiology and Virology of Riga Stradins University as well as a specialist at Center of Clinical Immunology of Pauls Stradins Clinical University Hospital.

She is a member of Latvian and Baltic Associations of Immunologists.

Romans Lacis was born in Kuldiga, Latvia, 1946, who received MD at Riga Medical Institute in 1970. Dr.med. (Candidate of Science in former USSR) at Riga Medical Institute in 1974 and Dr.habil.med (Doctor of Science in former USSR) at Riga Medical Institute in 1987. His main research interests are related to mechanics and ultrastructure of prosthetic heart valves.

He currently is a professor of Cardiac Surgery at Riga Stradins University, Riga, Latvia as well as head of the Centre of Cardiac Surgery at Pauls Stradins Clinical University Hospital in Riga, Latvia.

Prof. Lacis is a member of many local and international professional societies: European Society of Cardiology, European Association for Cardio-Thoracic Surgery, Society of Thoracic Surgeons, European Society for Cardiovascular Surgery and many others. He is the author of 200+ publications and has received many awards.

Iveta Ozolanta was born in Riga, Latvia, 1948, who received MD at Riga Medical Institute in 1973. Dr.med. (Candidate of Science in former USSR) at Kaunas Medical Academy, Lithuania in 1983 and Dr.habil.med (Doctor of Science in former USSR) at Medical Academy Of Latvia, Riga in 1998 Her research interests are centered on mechanical properties of various biological materials, those of the cardiovascular system being of special interest.

She currently is a professor and Vice-rector for Science at Riga Stradins University, Riga, Latvia. She is a Member of the Board in Latvian Association of Professors. She has served as a Coordinator of EU 5th and 6th Framework ERA-NET-AGE programs.

Prof. Ozolanta is a member of many local and international professional societies: European Society of Biomechanics, European Society of Tissue Engineering among many others.

Modra Murovska was born in Saldus, Latvia, 1949, who received MD at Riga Medical Institute in 1972. Dr.med. (Candidate of Science in former USSR) at Cancer Research Centre, USSR Academy of Medical Sciences, Moscow, Russia,1978. Her main research interests are centered around various onco-viruses.

She currently holds a position of an associate professor at Riga Stradins University, Riga, Latvia and is the Acting Director and Senior Researcher of August Kirchenstein Institute of Microbiology and Virology of Riga Stradins University, Riga, Latvia.

Prof. Murovska is a member of many local and international professional societies: American Society for Microbiology, European Society for Virology, European Association for Cancer Research among many others.

Vladimir Kasyanov was born in Peremyshlyany, Ukraine, 1946, who reeived MSc in Civil Engineering at Riga Polytechnic Institute, Riga, Latvia, 1969, and Candidate of Engineering Sciences (Ph.D.) at Institute of Polymer Mechanics, Latvian Academy of Science, Riga, 1977 followed by Doctor of Engineering Sciences (Dr.habil.sc.ing.) at Latvian Scientific Research Institute of Traumatology and Orthopedics, Riga, 1989. His main research interests are soft tissue biomechanics and tissue engineering.

$\mathrm{He}$ currently is a professor at Riga Stradins University, Riga, Latvia as well as the head of Laboratory of Biomechanics at Institute of Anatomy and Anthropology of Riga Stradins University, Riga, Latvia.

Prof. Kasyanov is a member of many local and international professional societies: European Tissue Engineering Society, European Biomechanics Society, International Community for Composites Engineering among many others. 